\title{
Quantitative measurement of Batrachochytrium dendrobatidis in amphibian skin
}

\author{
Ché Weldon*, Louis H. Du Preez \\ School of Environmental Sciences and Development, North-West University, Private Bag X6001, Potchefstroom 2520, \\ South Africa
}

\begin{abstract}
The ability to quantify infections provides a tool with which to perform comparative pathological research. The need exists for a simplistic standard method to compare infection levels of Batrachochytrium dendrobatidis, a major cause of global amphibian declines. Through examination of skin sloughs of the Cape river frog Afrana fuscigula, we present an accessible method that not only provides quantitative measurements of $B$. dendrobatidis, but also provides information that increases the confidence of detection through histological surveys. The method relies on the availability of live animals that are actively shedding skin. By employing a direct microscopic count of sporangia, it is possible to express infection in terms of density. Micro-spatial infection in the skin of A. fuscigula is characterised by significant differences in sporangium density among the different components of the foot, and by similar differences in site infection frequency. Notably, toe tips and tubercles contain higher infection densities and are more often infected than webbing or the base of the foot. This pattern of infection might facilitate disease transmission due to the increased exposure of these components to abrasion. Density data can be used with the Poisson frequency function to approximate binomial probabilities of detecting $B$. dendrobatidis through histology. The probability matrix produced for $A$. fuscigula indicated that foot-site selection for histology markedly influenced the number of sections required to detect $B$. dendrobatidis at a specific level of probability. Thus, examination of a test sample of skin tissue with direct-count quantification can help in planning the sampling of tissues for histological surveys.
\end{abstract}

KEY WORDS: Batrachochytrium dendrobatidis · Quantification technique · Sporangium density · Micro-spatial infection · Detection probability

\section{INTRODUCTION}

One of the major threats to amphibian biodiversity is the emerging infectious disease chytridiomycosis, caused by the amphibian chytrid fungus Batrachochytrium dendrobatidis (Daszak et al. 1999, Longcore et al. 1999). The disease has been associated with amphibian deaths and population declines in various parts of the globe, including North America, Central America, Australia, Europe and Africa (Berger et al. 1998, Carey et al. 1999, Bosch et al. 2001, Lips et al. 2003, Weldon \& Du Preez 2004). The amphibian chytrid develops in the outer keratinised layer of the epidermis in metamorphosed frogs and is concentrated in the region of the feet, hind legs and pelvic patch (Berger et al. 1998, Pessier et al. 1999). These areas of skin are the least susceptible to dehydration and are frequently in contact with water, which in turn increases exposure to the infective stage of the disease organism, namely water-borne zoospores.

Various microscopic techniques including wet mount examination of skin scrapes or shed skin, cytology and histology are used to identify chytridiomycosis, while other diagnostic tests specific for Batrachochytrium dendrobatidis that rely on immunohistochemistry and molecular properties have also been developed (Berger et al. 1999, Longcore 2001, Berger et al. 2002, Annis et al. 2004). However, except for the real-time 
PCR Taqman assay (Boyle et al. 2004), none of the methods serve as a tool for quantifying infection. The ability to quantify an infection has application in comparative experimental and basic research in the fields of pathology, immunology and epidemiology. The realtime PCR assay has many advantages because it operates with a high degree of sensitivity for diagnostic purposes in skin samples, with the ability to quantify infection down to a single zoospore (Boyle et al. 2004). Nonetheless, it does not provide quantitative information on the pattern of distribution on amphibian skin and is not readily available owing to the level of technology involved.

Several authors have made incidental comments on the intensity of infection while describing histologically observed microscopic lesions of infections from case reports of mortality events and the outcome of experimental transmission. In these references, infection intensity has been described in terms of degree of chytrid numbers (Nichols et al. 2001), percentage of skin surface infected on histological sections (Daszak et al. 2004, Hanselmann et al. 2004) and layers of infected keratinized cells (Burrowes et al. 2004, Daszak et al. 2004, Hanselmann et al. 2004). It becomes difficult to compare species or experimental groups when various methods are in use, of which the paired relationships have not been determined. Furthermore, the variability of Batrachochytrium dendrobatidis infection among toe clips, where not all toes of the same individual are infected, can often lead to false negatives in the data set (Boyle et al. 2004, Retallick et al. 2004), resulting in an under-representation of prevalence in populations. This variability becomes more apparent in animals with low levels of infection, thereby increasing the chances of overlooking the suspect organism. Therefore, a need exists for a standardised technique by which $B$. dendrobatidis infection can be quantified not just for comparative research, but also for providing accurate information that will increase the confidence of detecting infection through histological surveys. Such a technique should be accessible to most workers in the field and should preferably not require advanced skills beyond accurately diagnosing amphibian chytrid infection.

In this study we present a quantification technique for Batrachochytrium dendrobatidis in apparently healthy and moribund frogs that makes use of one of the most commonly noted clinical symptoms of chytridiomycosis, namely the tendency to slough skin more frequently. Sloughed skin contains clusters of chytrid thalli, the abundance and distribution of which corresponds to the section of skin on the donor frog. By utilising this sloughed skin, infection can be quantified by determining sporangium density across the foot. An imprint of the foot is left in skin sloughs in which the different components of the foot (toes, webbing etc.) can be distinguished from each other. The procedures for quantification are demonstrated on the Cape river frog Afrana fuscigula, a common inhabitant of rivers, streams and dams in the Western Cape, Eastern Cape and parts of the Northern Cape provinces as well as the central plateau of South Africa. In addition, morphology of the hind feet was used to characterise the micro-spatial distribution of infection. The feet of $A$. fuscigula are extensively webbed, pointed toes contain sub-articular tubercles, and an inner metatarsal tubercle is present on the base of the foot. This paper presents 3 sets of information pertaining to the quantification technique: (1) a step-by-step approach to quantify infection by $B$. dendrobatidis, (2) characterisation of $B$. dendrobatidis infection in A. fuscigula, and (3) application of the quantification technique in the selection of tissue types for histological diagnosis of chytridiomycosis.

\section{MATERIALS AND METHODS}

Source and collection of specimens. During May 2004, a disease survey of frogs was carried out in the semi-desert Namaqualand region in the Northern Cape Province of South Africa, which forms part of the Succulent Karoo biome. A large population of Afrana fuscigula inhabiting a shallow stream on privately owned land on the plateau of the Kammiesberg (altitude $1100 \mathrm{~m}$ ) was used as the source of study animals. The perennial stream was fed by seepage from a pond, built in a riverbed that only received water during a short rain season in winter (May to July). No moribund or sick frogs were observed, and apparently healthy adults were collected and placed in separate containers that were transported in large cooler boxes. Frogs were individually housed in an air-conditioned room $\left(20^{\circ} \mathrm{C}\right)$ in rectangular plastic containers $(220 \times 120 \times$ $170 \mathrm{~mm}$ ) with ventilated lids. The containers were fitted with a raised platform that divided the base into wet and dry areas.

Quantification of sporangia in skin sloughs. Preparation of sloughed skin samples: Each frog was placed in a separate container with $100 \mathrm{ml}$ dechlorinated tap water and left for $24 \mathrm{~h}$ in a temperature-controlled room $\left(20^{\circ} \mathrm{C}\right)$ that allowed time for the sloughing of skin. Skin sloughs from the hind feet (identified by their shape and presence of dense impressions from the tubercles) were removed from water baths and transferred to microscope slides. Two sharp needles were used to spread out the skin evenly over the slide with the tubercles facing upward, under observation with a dissecting microscope. Cover slips were added and the specimens observed with a compound micro- 
scope. Skin sloughs from all frogs were screened for amphibian chytrid infection in this way, but only whole skin sloughs (foot base and 5 toes intact) were selected for the counting of sporangia.

Counting of zoosporangia: The following methodology was used:

(1) Select the $40 \times$ objective of the compound microscope and place the stage micrometer in position on the mechanical stage.

(2) Measure the diameter of the microscopic field of view.

(3) Calculate the area of the microscopic field by using the equation $\pi r^{2}$.

(4) Align the prepared slide so that an imaginary line through the longest section of the skin slough is parallel with the $x$-axis of the microscope stage (Fig. 1) This ensures that, by turning the $x$-axis adjustment knob of the microscope, the observer will not deviate from the imaginary line transecting the longest section.

(5) Starting at one end of the skin slough and, while moving the slide along the designated axis, count sporangia within each field for the entire length of the skin slough. Note that because fields do not overlap, but touch at the edges, 2 roughly triangular areas (with concave sides) will be omitted between adjacent fields.

(6) Align the slide so that the widest section of the skin slough is parallel with the $y$-axis of the microscope stage. The designated axis along the width of the skin slough is therefore at a right angle with the $y$ axis (Fig. 1).

(7) Starting at one end of the skin slough and moving the slide along the designated axis, count sporangia within each field for the entire width of the skin slough.

(8) Calculate mean number of sporangia observed per field of view for all fields included in the $x$ - and $y$ axes. Convert to sporangia $\mathrm{mm}^{-2}$ using the known microscope field area.

Additional count data and measurements. Sporangium density was also calculated for different sites relating to the components of the feet, namely toes, toe tips, tubercles, webbing and base of the foot. Skin sloughs from all 25 infected frogs were used for this analysis regardless of the degree to which the foot skin slough was intact. The components were easily distinguished from one another in sloughed skin by their shape, surface texture and relative position to one another (Fig. 2). Sporangium counts were made in microscope fields along a single straight line from the proximal to the distal end of each component. The number of each component that was measured varied with the degree to which the skin slough was intact.
Dimensions of sporangia and cluster size were measured with an eyepiece graticule and expressed as mean \pm SD. Groups of sporangia were defined as clusters when the area of uninfected skin between such groups was wider than the diameter of the larger of 2 adjacent groups. Only groups of $\geq 10$ sporangia were measured to determine cluster size. In addition, cluster density (mean no. of clusters $\mathrm{mm}^{-2}$ ) was calculated for each of the 5 components of the foot. While the sporangium counts were made, the number of clusters was noted. Because the area of the microscopic field was known, cluster density could be calculated. Specimens were again screened for sporangia of Batrachochytrium dendrobatidis after $4 \mathrm{wk}$ in captivity to confirm infection status.

Statistical analysis. All statistical analyses were computed using the Statistica 7 software package. The Shapiro-Wilk's test was used to test for normality of count data (sporangia per field). Transformations were performed on count data by using log, square root and square transformations. Kruskal-Wallace tests were used to analyse bivariate associations among the densities of Batrachochytrium dendrobatidis on the toes, toe tips, tubercles, webbing and foot base.

The Poisson frequency function, presented by Rice (1995), was used to approximate binomial probabilities of detecting Batrachochytrium dendrobatidis on a $3 \times$ $3 \mathrm{~mm}$ skin sample when using histology as diagnostic tool. The calculations made use of the principle that sporangia were grouped together in clusters, that all sections were of equal size $(6 \mu \mathrm{m})$, and were based on the assumption that data followed a Poisson distribution.

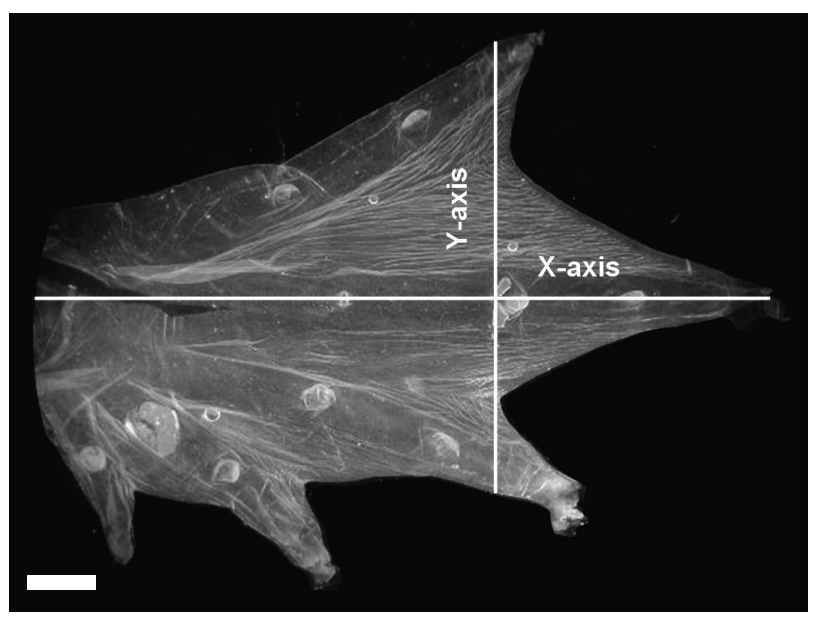

Fig. 1. Afrana fuscigula. Wet mount of sloughed skin from the foot. Perpendicular lines indicate longest ( $x$-axis) and widest ( $y$-axis) sections of skin. Sporangia counts were made within each microscopic field for the entire length of both axes, and were used to calculate sporangium density. Scale bar $=2.5 \mathrm{~mm}$ 

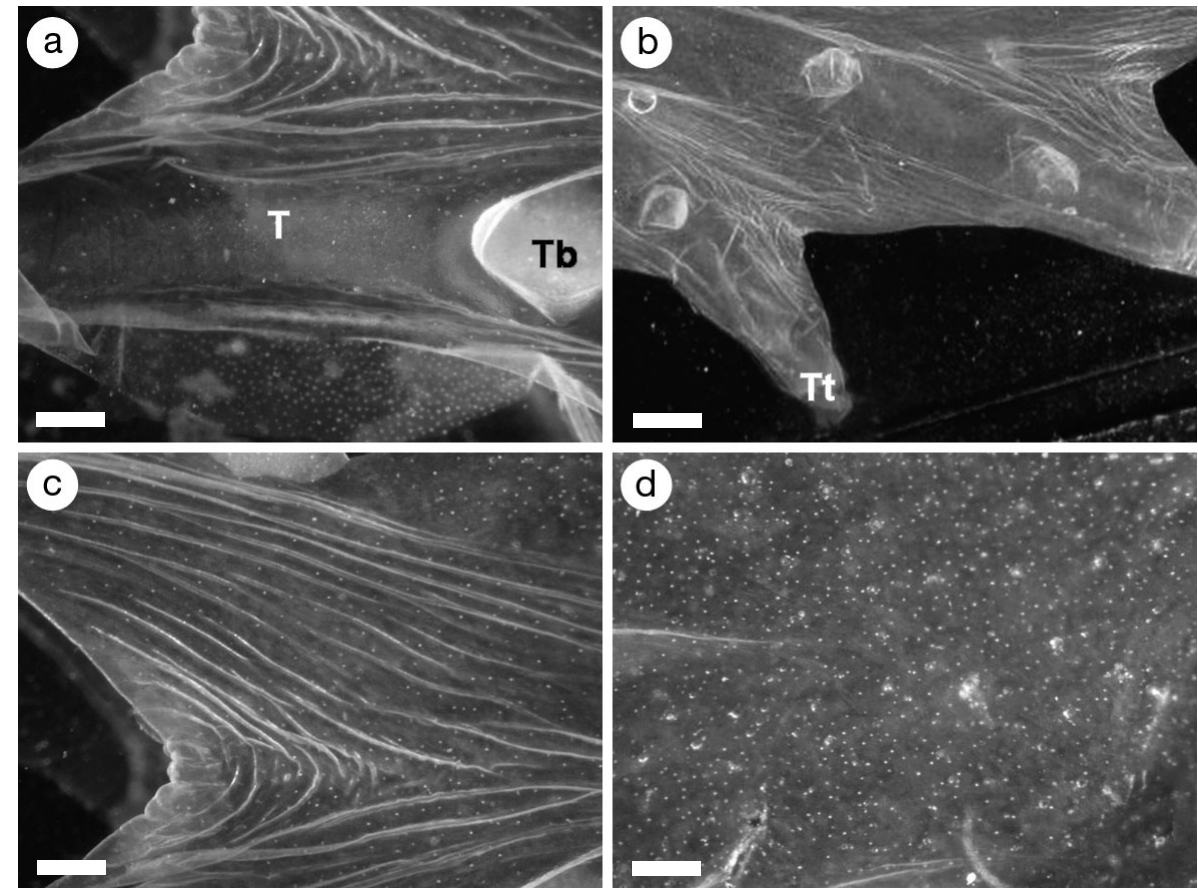

Fig. 2. Afrana fuscigula. Imprints on sloughed skin left by components of the anuran foot. Components are distinguished from one another by their shape, texture and position relative to each other. (a) Toes have a smooth appearance and are interrupted with $\geq 1$ oval shaped, heavily keratinized tubercles; T: toe, Tb: tubercle. Scale bar $=0.5 \mathrm{~mm}$. (b) Toe tips are situated at the distal end of toes and are more heavily keratinized than the rest of the toe; Tt: toe tip. Scale bar $=1 \mathrm{~mm}$. (c) Webbing is found in between toes and has numerous small folds. Scale bar $=0.3 \mathrm{~mm}$. (d) The foot base consists of smooth, thin tissue. Scale bar $=0.3 \mathrm{~mm}$

\section{RESULTS}

\section{Diagnosis and infection rate}

Batrachochytrium dendrobatidis-infected skin sloughs were distinguished from healthy skin by the presence of 1 or more sporangia that disrupted the mosaic pattern of squamous epithelial cells. Mean sporangium size $( \pm \mathrm{SD})$ was determined to be $6.9 \pm 1.6 \mu \mathrm{m}(\mathrm{n}=113)$, and maximum sporangium size was $11.7 \mu \mathrm{m}$. Sporangia in various stages of development were often observed within the same cluster, especially young sporangia and mature sporangia with colonial morphology, zoospores and discharge papilla. Fewer empty sporangia were observed. The centre of larger clusters often lacked sporangia but retained hyperkeratotic tissue brought on by infection, thereby appearing as donut-shaped clusters (Fig. 3). Infected epithelial cells associated with smaller clusters had a flaky appearance because of partial or complete detachment. Small clusters from the base of the foot were often associated with elevated epidermal cells that resemble microscopic warts.

Prevalence was high at $61 \%(n=25$ from 41$)$ at the time of capture. Apart from excessive sloughing of the skin, no other clinical symptoms usually associated with chytridiomycosis were observed at the time. After 1 mo in captivity, all experimental animals were still alive and Batrachochytrium dendrobatidis could only be detected in $9.8 \%(\mathrm{n}=4$ from 41$)$ of frogs. All except 1 of the 16 frogs that initially tested negative for chytridiomycosis remained uninfected.

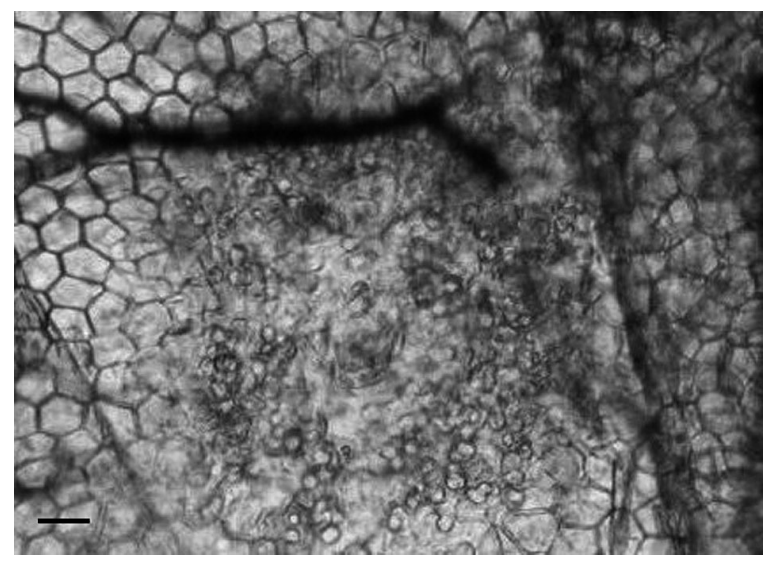

Fig. 3. Afrana fuscigula. Light micrograph of toe skin infected with Batrachochytrium dendrobatidis. Pattern of squamous epithelium is disrupted by a cluster of thalli that form an expanding ring around a core of uninfected keratinized skin cells, to form a characteristic donut-shaped cluster. Scale bar $=20 \mu \mathrm{m}$ 


\section{Zoosporangium density}

Whole skin sloughs that could be used for the quantification of Batrachochytrium dendrobatidis were attained from 13 infected frogs. Sporangium density among specimens ranged from 1.0 to $533.4 \mathrm{~mm}^{-2}$ with mean $55.2 \mathrm{~mm}^{-2}$. Even larger differences in sporangia per field were counted, from 0 to a minimum of $3.71 \mathrm{~mm}^{-2}$, to a maximum of $2228 \mathrm{~mm}^{-2}$. These values were calculated from 575 fields of which $18.8 \%$ had sporangia, totalling 8536 sporangia. The majority of fields with sporangia (74.1\%) were adjoined on either one or both sides by fields in which sporangia were detected, resulting in a series of mostly empty fields interrupted by clumped fields with sporangia and less frequently by only single fields with sporangia. Cluster size was highly variable and was not only affected by the number of sporangia but also by density of sporangia. As an indication of this variation, mean size of clusters of 10 sporangia was $572.4 \pm 203.4 \mu^{2}$. One cluster of 135 sporangia covered an area of $0.043 \mathrm{~mm}^{2}$, whereas another cluster of 177 measured just $0.009 \mathrm{~mm}^{2}$. Small clusters usually conformed to a circular or elliptical shape, but clusters became more variable with increased cluster size.

\section{Zoosporangium density per site}

High sporangium density on tubercles and a large component of observations without any sporangia contributed to a normality curve that was skewed to the right. None of the transformations produced a normal distribution; hence, count data were analysed with non-parametric tests. Overall, sporangium density across the different sites on the foot differed significantly from each other $(p=0.001)$, indicating that sporangia were not evenly spread over the ventral surface of the foot. Multiple paired comparisons of mean ranks of sporangium density from all sites indicated that a significant difference $(p=0.0091)$ existed between the density on toe tips and on webbing. The pattern of sporangium density that emerged from comparison of the density variables of the sites indicated that density decreased from the distal end of the foot (toe tip) to the proximal end (foot base), and from the elevated region (tubercles) to the lower region of the webbing.

Infection of the foot could be divided into 3 categories according to sporangia density (Table 1), namely a high-density site (toe tips, $160.8 \mathrm{~mm}^{-2}$ ), moderate-density sites that included tubercles $\left(58.4 \mathrm{~mm}^{-2}\right)$ and toes $\left(56.4 \mathrm{~mm}^{-2}\right)$, and low-density sites that included the webbing $\left(7.4 \mathrm{~mm}^{-2}\right)$ and foot base $\left(5.9 \mathrm{~mm}^{-2}\right)$. Toe tips and tubercles had the smallest surface area and often contained dense clusters of sporan- gia. In contrast, sites that had large areas such as the foot base and webbing (extensive in Afrana fuscigula) had only isolated clusters of sporangia. In only $16.7 \%$ of infected specimens were all 5 sites infected. Most often $(41.7 \%$ of infected specimens), the infection was restricted to 2 sites only. Differences were also observed in terms of the frequency with which sites were infected. The most frequently infected site was toes (62.1\% of specimens); toes were infected twice as often as tubercles and the base of the foot, and more than 3 times as often as webbing.

\section{Probability of detecting infection through histology}

The occurrence of chytrid clusters on the skin fit the Poisson distribution when the following 2 assumptions are made. Firstly, although a variation in cluster size exists that may influence detection probability, the total surface area covered by clusters in relation to the surface area of the skin being sectioned is negligibly small. Mean total surface area covered by clusters varied between 0.2 and $0.6 \%$ of the skin being sectioned (Table 2): an equivalent of 1 to 3 sections out of 500 possible sections of a $3 \times 3 \mathrm{~mm}$ skin sample. Secondly, clusters are independent and there is no reason for

Table 1. Comparison of Batrachochytrium dendrobatidis sporangium density on different sites of Afrana fuscigala feet and the number of fields from which sporangia $\mathrm{mm}^{-2}$ were calculated

\begin{tabular}{|lccc|}
\hline Site & $\begin{array}{c}\text { No. samples } \\
\text { examined }\end{array}$ & $\begin{array}{c}\text { No. fields } \\
\text { (avg. per } \\
\text { sample) }\end{array}$ & $\begin{array}{c}\text { Sporangium } \\
\text { density } \\
\text { (mean } \pm \text { SD) }\end{array}$ \\
\hline Toe tips & 26 & $39(1.5)$ & $160.8 \pm 241.8$ \\
Tubercles & 63 & $102(1.6)$ & $58.4 \pm 69.5$ \\
Toes & 29 & $353(12.2)$ & $56.4 \pm 70.7$ \\
Webbing & 28 & $199(7.2)$ & $7.4 \pm 13.3$ \\
Foot base & 22 & $206(9.4)$ & $5.9 \pm 10.4$ \\
\hline
\end{tabular}

Table 2. Values and formulas used to calculate \% surface area covered by Batrachochytrium dendrobatidis on $1 \mathrm{~mm}^{2}$ of Afrana fuscigula skin. Value for $\mathrm{r}$ derived from mean sporangium size (diameter) for all samples $(6.9 \mu \mathrm{m})$

\begin{tabular}{|lccc|}
\hline Site & $\begin{array}{c}\text { Sporangia } \mathrm{mm}^{-2} \\
\boldsymbol{X}\end{array}$ & $\begin{array}{c}\text { Area }\left(\mathrm{mm}^{2}\right) \\
y=\pi \mathrm{r}^{2} \mathrm{x}\end{array}$ & $\begin{array}{c}\% \text { Cover } \\
y / 1 \%\end{array}$ \\
\hline Whole foot & 55.2 & 0.002065 & 0.21 \\
Toe tip & 160.8 & 0.006015 & 0.60 \\
Tubercle & 85.4 & 0.003195 & 0.32 \\
Toe & 56.4 & 0.002110 & 0.21 \\
Webbing & 7.4 & 0.000277 & 0.03 \\
Foot base & 5.9 & 0.000221 & 0.02 \\
\hline
\end{tabular}


clusters to group together; they will instead be randomly distributed on the skin. Mean cluster density on a $9 \mathrm{~mm}^{2}$ skin sample increased in the same order among sites as did sporangium density, namely foot base (1.57 clusters), webbing (2.22 clusters), toe (8.61 clusters), tubercle (10.88 clusters) and toe tip (12.0 clusters). Because cluster density varied among sites on the foot, the random distribution of clusters applied to distribution within the individual sites rather than to the whole foot. Because the Poisson frequency function is dependent on cluster density, the number of sections required for each level of probability increased proportionately with the decreasing cluster density of sites (Table 3).

In this study, detection of Batrachochytrium dendrobatidis in Afrana fuscigula with $95 \%$ probability required 125 sections through a toe tip sample, 138 sections through a tubercle sample or 174 sections through toe tissue. Note that these numbers do not refer to the minimum number of sections needed to detect $B$. dendrobatidis, but refer to the probability that $B$. dendrobatidis would be detected when a given number of sections through a toe tip sample were made (e.g. 95\% probability for 125 sections). Therefore, $B$. dendrobatidis could be detected in the first, the 125 th, or in any section in between. When sectioning webbing of A. fuscigula, detection of $90 \%$ probability or more would require more than 500 sections and therefore a larger tissue sample. The cut-off probability of a $9 \mathrm{~mm}^{2}$ foot base sample is closer to $80 \%$. A clear difference in work effort is therefore required between skin samples of varying cluster density.

Table 3. Probability matrix for detecting Batrachochytrium dendrobatidis through a given number of histological sections on a $3 \times 3 \mathrm{~mm}$ piece of Afrana fuscigula skin, derived from Poisson frequency function. Differences in required number of sections for a given probability level were accounted for by mean number of clusters

\begin{tabular}{|c|c|c|c|c|c|}
\hline \multirow[t]{2}{*}{ Probability } & \multicolumn{5}{|c|}{ No. of sections } \\
\hline & Toe tip & Tubercle & Toe & Webbing & Foot base \\
\hline 0.1 & 4 & 5 & 6 & 24 & 34 \\
\hline 0.2 & 9 & 10 & 13 & 50 & 71 \\
\hline 0.3 & 15 & 16 & 21 & 80 & 113 \\
\hline 0.4 & 21 & 23 & 30 & 115 & 163 \\
\hline 0.5 & 29 & 32 & 40 & 156 & 221 \\
\hline 0.6 & 38 & 42 & 53 & 206 & 292 \\
\hline 0.7 & 50 & 55 & 70 & 271 & 383 \\
\hline 0.8 & 67 & 74 & 93 & 362 & $512^{\mathrm{a}}$ \\
\hline 0.9 & 96 & 106 & 134 & $519^{\mathrm{a}}$ & $733^{\mathrm{a}}$ \\
\hline 0.95 & 125 & 138 & 174 & $675^{\mathrm{a}}$ & $954^{\mathrm{a}}$ \\
\hline 0.99 & 192 & 212 & 267 & $1037^{a}$ & $1476^{\mathrm{a}}$ \\
\hline
\end{tabular}

\section{DISCUSSION}

\section{Direct microscopic count as quantification technique}

The case study of Afrana fuscigula has demonstrated that it is possible to reliably quantify Batrachochytrium dendrobatidis infection in apparently healthy frogs, using a technique that can also be used on moribund frogs. The technique may be harder to use on sub-clinically infected animals with low organism numbers. Because it is difficult to harvest whole foot sloughs every time a frog sheds its skin, owing to uneven shedding or mechanical damage, whole foot sloughs will only be collected from a proportion of experimental animals on any given day. The likelihood of collecting whole foot sloughs from all animals therefore increases with the number of days that skin is harvested. However, results would be less reliable if infection intensity were to change over time due to some environmental factor. The application of quantification data from intra-population differences to comparative susceptibility, transmission and pathogenisity studies among species requires further investigation. During such investigations, it must be considered that different amphibians shed skin at different rates and that skin slough size may be speciesor situation-dependent.

Caution should be excercised when the technique is used on terrestrial frogs that are known to drown easily (e.g. members of the Microhylidae family). Although this technique has not yet been tested on salamanders, sloughed skin has been used to diagnose Batrachochytrium dendrobatidis infection in this group of amphibians (Davidson et al. 2003). The morphological similarities of salamander feet to those of anurans, and their ability to shed skin from the feet in large pieces, suggest that it will be possible to use the quantification technique on salamanders (E. W. Davidson pers. comm.). Because this technique requires actively shedding animals, it cannot be used to quantify infection in material from die-offs of amphibians or from archived material.

In fully aquatic amphibians, infection is not necessarily limited to the hind legs and ventrum but may also include the dorsal surfaces, as observed in African clawed frogs Xenopus spp. (Parker et al. 2002). Prevalence of $100 \%$ was detected in X. laevis populations when only interdigital webbing was examined $(C$. Weldon unpubl. data), suggesting that infection is more evenly distributed across the foot than in A. fuscigula. If no significant difference in distribution across the foot exists in aquatic frogs, site selection among this group of amphibians is not imperative when collecting tissue for histological diagnostic techniques such as conventional histology (e.g. haematoxylin and 
eosin staining) and the chytrid-specific immunoperoxidase test of Berger et al. (2002).

As a diagnostic tool, the use of whole pieces of skin slough instead of skin scrapings has advantages regarding the ease of screening, in that skin scrapings often contain pigmented cells that make it more difficult to distinguish Batrachochytrium dendrobatidis sporangia. Furthermore, sloughed skin usually consists of fewer cell layers than do skin scrapings (e.g. epidermis and dermis tissue), which eases focusing through the tissue sample. The advantage of maintaining anatomical relationships when examining sloughed skin is that the observer can easily establish which layer is being observed by orientation from the surface. This is important for locating sporangia that are usually restricted to the upper layers. This orientation is lost in skin scrapings, and deciding whether suspicious structures are at the surface or within deeper layers is often difficult owing to the disruption of the relationship of the layers. On the other hand, skin scrapings are favoured when attempts are made at isolating $B$. dendrobatidis, because sloughed skin is usually more contaminated with bacteria and other fungi that outcompete the amphibian chytrid when grown on nutrient agar.

\section{Infection in Afrana fuscigula}

Despite the high prevalence and relatively heavy infections in some Afrana fuscigula, infected frogs did not appear to be adversely affected by Batrachochytrium dendrobatidis and $84 \%$ were able to clear the infection after a month in captivity. The increase in ambient temperature from the field to captivity was not likely to have been responsible for the observed clearance of infection, because the temperature change was within the growth optimum of $B$. dendrobatidis, see Longcore et al. (1999). Tadpoles of Afrana fuscigula have a slow development that may take up to 2 yr to complete (Du Preez 1996). Infected tadpoles could therefore act as reservoir hosts to $B$. dendrobatidis that could facilitate continuous transmission to metamorphosed frogs, especially because A. fuscigula is semiaquatic and shares the same habitat as its tadpoles. The separation of $A$. fuscigula from the tadpole source of $B$. dendrobatidis when relocated to the laboratory may have reduced the exposure potential to these animals. Frogs that spent a lot of time on the elevated sections of enclosures would have experienced a reduction in exposure time to zoospores in the water, further contributing to the animals becoming cleared of infection by $B$. dendrobatidis.

The observed clearance of infection is contrary to previous reports of chytridiomycosis in wild Afrana fuscigula, where mortality events and sporadic deaths of juvenile and adult frogs occurred in populations in Namaqualand and the Eastern Cape Province (Hopkins \& Channing 2003, Lane et al. 2003). It seems that the outcome of infection in this species is variable and that advancement to mortality may depend on the presence of tadpoles and host behaviour, in addition to temperature sensitivity of the fungus, which has been implicated in other species (Woodhams et al. 2003). In 1996, at a site less than $200 \mathrm{~km}$ from the source of frogs of the present study, a population of nearly $50 \mathrm{~A}$. fuscigula died at the start of the wet season after a prolonged period of drought. In a retrospective examination on 5 of the dead specimens collected at the site, we detected a $100 \%$ prevalence of $B$. dendrobatidis. Variation in susceptibility to chytridiomycosis within a species has been demonstrated in experimentally infected Rana yavapaiensis and Rana boylii and in the tiger salamander Ambystoma tigrinum (Davidson et al. 2003). It would therefore appear that A. fuscigula exhibits a degree of resistance to chytridiomycosis as long as optimum environmental conditions prevail.

\section{Micro-spatial infection on skin}

The wide range of differences in sporangium density among individuals of the population could be due to the length of infection or could reflect the possibility that some animals had recently shed skin, resulting in the detection of fewer sporangia during examination. It can be expected that recently infected individuals will not be as heavily infected as those that have carried the infection for an extended period of time. Withinspecimen variation in sporangium density per field is symptomatic of an over-dispersed infection. The frequent occurrence of sporangia in adjoining fields indicates that Batrachochytrium dendrobatidis occurs in clusters in the skin. The aggregation of sporangia in clusters could be a direct result of the colonisation strategy of the organism, whereby colonies have a tendency to expand concentrically from the original loci of infection resulting in a core of hyperkeratotic tissue devoid of sporangia.

Cluster growth is also promoted by the ability of zoospores to swim for short distances and for a limited time before they encyst (Piotrowski et al. 2004). A similar growth pattern appears in Batrachochytrium dendrobatidis colonies grown on nutrient agar, with zoospores that tend to encyst at the edges of existing colonies that gradually expand as a consequence of this behaviour. It appears that after the core of clusters or older sporangia have been shed, the hyperkeratotic tissue at the centre of the cluster does not immediately become recolonised, resulting in a donut-shaped clus- 
ter. Therefore, low sporangium counts per field may reflect an area of recent infection or an area at the periphery of an expanding cluster, whereas high sporangium densities may be counted in the active growing regions of older clusters. Experimental work is required to establish if and how skin tissue that lack normal anatomical arrangements (e.g. hyperkeratosis) influences the ability of zoospores to penetrate skin, and if the amphibian host could develop local resistance to $B$. dendrobatidis in areas that were previously infected.

Differences in sporangium densities among different areas of the foot, as well as site infection frequency, indicate that although any area of the foot is likely to become infected, certain areas are more likely to remain heavily infected. The most heavily infected sites on the foot (toe tips, tubercles and toes) are also the areas that are in particularly close contact with the substrate (due to the protruding surfaces of the tubercles and toe tips and the clasping ability of the toes), and are thus the most likely areas to encounter zoospores on wet substrates. Of further significance is that the toes and protruding areas are more heavily keratinized, thus providing more usable substrate for the fungus, and are most likely subjected to abrasion during contact with the substrate or other frogs during amplexus (the mating ritual). Therefore, these areas may greatly contribute to the spread and direct transmission of the fungus as a result of the concentration of infection in areas that are exposed to severe abrasion.

\section{Use of density data in histology}

This study demonstrated that examination of a test sample of skin sloughs provides data that can help to plan a histological survey. When selecting tissue types for histological diagnosis, quantification data can provide information on (1) the part of the foot that must be selected for histology (2) the minimum number of the identified part that must be collected from each specimen if the particular part occurs in multiples (all parts except foot base) and (3) the number of sections that need to be made in order to detect infection at a certain level of probability in a given population of frogs. The probability of detecting Batrachochytrium dendrobatidis is not only a factor of sporangia density in a site, but also the frequency with which the site is infected in a population sample. The probability matrix produced by the Poisson frequency function illustrated that site selection for histological analysis can have a marked influence on the number of sections required to detect the amphibian chytrid at a specific level of probability. Further histological examination involving comparisons among samples selected through this technique and among randomly collected samples could provide experimental evidence for the efficiency of the quantification technique in eliminating false negatives from population data.

\section{CONCLUSIONS}

The direct microscopic count technique for quantifying Batrachochytrium dendrobatidis infection in live frogs does not require high-level technology and yields reliable data that can be summarised as follows: (1) the direct sporangium count makes it possible to express infection in terms of sporangia density, thus quantifying the infection, (2) comparing sporangium densities among different sites provides a method to determine which part of the foot must be used in histological surveys to provide the best chance of detecting $B$. dendrobatidis and (3) applying sporangium density data to the histological technique allows calculation of the probability of detecting chytridiomycosis through set section repetitions.

The application of this technique to quarantine regulations that involve daily examinations is encouraged, as it not only provides non-invasive presence/absence data but also allows the investigator to quantify the response of chytridiomycosis to treatment regimes. Regular surveillance of amphibians has already been instigated at scientific laboratories and on frog farms following chytridiomycosis epidemics (Parker et al. 2002, Mazzoni et al. 2003). Further research is needed in order to determine the minimum requirement of skin slough size useful for the detection of chytridiomycosis. It should be noted that, in comparison with frogs with major infections, frogs with early or light infections often do not shed as much skin and infection is not as easy to detect, and that in these cases the minimum skin slough size is likely to be dependent on the situation or species.

Acknowledgements. We acknowledge R. Speare and J. Longcore for useful commentary on earlier versions of this manuscript. We thank W. Conradie for technical assistance during fieldwork.

\section{LITERATURE CITED}

Annis SL, Dastoor FP, Ziel H, Daszak P, Longcore JE (2004) A DNA-based assay identifies Batrachochytrium dendrobatidis in amphibians. J Wildl Dis 40:420-428

Berger L, Speare R, Daszak P, Green DE and 10 others (1998) Chytridiomycosis causes amphibian mortality associated with population declines in the rain forests of Australia and Central America. Proc Natl Acad Sci 95:9031-9036

Berger L, Speare R, Kent A (1999) Diagnosis of chytridiomycosis in amphibians by histologic examination. Zoos Print J 15:184-190 
Berger L, Hyatt AD, Olsen V, Hengstberger S, Boyle D, Marantelli G, Humphreys K, Longcore JE (2002) Production of polyclonal antibodies to Batrachochytrium dendrobatidis and their use in an immunoperoxidase test for chytridiomycosis in amphibians. Dis Aquat Org 48: 213-220

Bosch J, Martínez-Solano I, García-París M (2001) Evidence of a chytrid fungus infection involved in the decline of the common midwife toad (Alytes obstetricans) in protected areas of central Spain. Biol Conserv 97:331-337

Boyle DG, Boyle DB, Olsen V, Morgan JAT, Hyatt AD (2004) Rapid quantitative detection of chytridiomycosis (Batrachochytrium dendrobatidis) in amphibian samples using real-time Taqman PCR assay. Dis Aquat Org 60:141-148

Burrowes PA, Joglar RL, Green DE (2004) Potential causes for amphibian declines in Puerto Rico. Herpetologica 60: 141-154

Carey C, Cohen N, Rollins-Smith L (1999) Amphibian declines: an immunological perspective. Dev Comp Immunol 23:459-472

Daszak P, Berger L, Cunningham AA, Hyatt AD, Green DE, Speare R (1999) Emerging infectious diseases and amphibian declines. Emerg Infect Dis 5:735-748

Daszak P, Strieby A, Cunningham AA, Longcore JE, Brown CC, Porter D (2004) Experimental evidence that the Bullfrog (Rana catesbeiana) is a potential carrier of chytridiomycosis, an emerging fungal diseases of amphibians. Herpetol J 14:201-207

Davidson EW, Parris M, Collins JP, Longcore JE, Pessier AP, Brunner J (2003) Pathogenisity and transmission of chytridiomycosis in tiger salamanders (Ambystoma tigrinum). Copeia 2003:601-607

Du Preez LH (1996) Field guide and key to the frogs and toads of the Free State. University of the Free State, Bloemfontein

Hanselmann R, Rodríguez A, Margarita L, Fajardo-Ramos L, Aguirre AA, Kilpatrick AM, Rodríguez JP, Daszak P (2004) Presence of an emerging pathogen of amphibians in introduced bullfrogs Rana catesbeiana in Venezuela. Biol Conserv 120:115-119

Hopkins S, Channing A (2003) Chytrid fungus in Northern and Western Cape frog populations, South Africa. Herpetol Rev 34:334-336

Lane EP, Weldon C, Bingham J (2003) Histological evidence

Editorial responsibility: Alex Hyatt,

Geelong, Victoria, Australia of chytridiomycosis in a free-ranging amphibian, Afrana fuscigula (Anura: Ranidae), in South Africa. J S Afr Vet Assoc 74:20-21

Lips KR, Reeve JD, Witters LR (2003) Ecological traits predicting amphibian population declines in Central America. Conserv Biol 17:1078-1088

Longcore JE (2001) Culture techniques for amphibian chytrids: recognizing, isolating, and culturing Batrachochytrium dendrobatidis from amphibians. In: Speare R (ed) Developing management strategies to control amphibian diseases: decreasing the risks due to communicable diseases. James Cook University, Townsville, p 52-54

Longcore JE, Pessier AP, Nichols DK (1999) Batrachochytrium dendrobatidis gen. et sp. nov., a chytrid pathogenic to amphibians. Mycologia 91:219-227

Mazzoni R, Cunningham AA, Daszak P, Apolo A, Perdomo E, Speranza G (2003) Emerging pathogen of wild amphibians in frogs (Rana catesbeiana) farmed for international trade. Emerg Infect Dis 9:995-998

Nichols DK, Lamirande EW, Pessier AP, Longcore JE (2001) Experimental transmission of cutaneous chytridiomycosis in dendrobatid frogs. J Wildl Dis 37:1-11

Parker JM, Mikaelian I, Hahn N, Diggs HE (2002) Clinical diagnosis and treatment of epidermal chytridiomycosis in African clawed frogs (Xenopus tropicalis). Comp Med 52: 265-268

Pessier AP, Nichols DK, Longcore JE, Fuller MS (1999) Cutaneous chytridiomycosis in poison dart frogs (Dendrobates spp.) and Whit's tree frogs (Litoria caerulea). J Vet Diag Invest 11:194-199

Piotrowski JS, Annis SL, Longcore JE (2004) Physiology of Batrachochytrium dendrobatidis, a chytrid pathogen of amphibians. Mycologia 96:9-15

Retallick RWR, McCallum H, Speare R (2004) Endemic infection of the amphibian chytrid fungus in a frog community post-decline. PLoS Biol 2:e351

Rice JA (1995) Mathematical statistics and data analysis, 2nd edn. Duxbury Press, Belmont

Weldon C, Du Preez LH (2004) Decline of the Kihansi Spray Toad, Nectophrynoides asperginis, from the Udzungwa Mountains, Tanzania. Froglog 62:2-3

Woodhams DC, Alford RA, Marantelli G (2003) Emerging disease of amphibians cured by elevated body temperature. Dis Aquat Org 55:65-67

Submitted: March 13, 2006; Accepted: August 18, 2006

Proofs received from author(s): October 9, 2006 